\title{
STARLIKENESS OF A CROSS-PRODUCT OF BESSEL FUNCTIONS
}

\author{
Huda A. Al-Kharsani, Árpád Baricz And Tibor K. Pogány
}

\begin{abstract}
In this paper a necessary and sufficient condition is deduced for the close-to-convexity of a cross-product of Bessel and modified Bessel functions of the first kind and their derivatives by using a result of Shah and Trimble about transcendental entire functions with univalent derivatives, the newly discovered power series and infinite product representation of this crossproduct, as well as a slightly modified version of a result of Lorch on the monotonicity of the zeros of the cross-product with respect to the order.
\end{abstract}

Mathematics subject classification (2010): 33C10, 30C45.

Keywords and phrases: Bessel functions of the first kind, modified Bessel functions of the first kind, close-to-convex functions, starlike functions, transcendental entire functions, zeros of cross-product of Bessel functions, infinite product.

\section{REFERENCES}

[1] M. Abramowitz, I. A. Stegun (Eds.), Handbook of Mathematical Functions with Formulas, Graphs, and Mathematical Tables, Dover, New York, 1972.

[2] G. E. Andrews, R. Askey, R. Roy, Special Functions, Cambridge University Press, Cambridge, 1999.

[3] Á. BARICZ, Geometric properties of generalized Bessel functions, Publ. Math. Debrecen 73 (2008), $155-178$.

[4] Á. BARICZ, Generalized Bessel Functions of the First Kind, Lecture Notes in Mathematics, vol. 1994, Springer-Verlag, Berlin, 2010.

[5] Á. BARICZ, P. A. KupÁN, R. SZÁsz, The radius of starlikeness of normalized Bessel functions of the first kind, Proc. Amer. Math. Soc. 142 (6) (2014), 2019-2025.

[6] Á. Baricz, S. Ponnus Amy, Starlikeness and convexity of generalized Bessel functions, Integr. Transforms Spec. Funct. 21 (2010), 641-653.

[7] Á. Baricz, S. Ponnus Amy, S. Singh, Cross-product of Bessel functions: monotonicity patterns and functional inequalities, Proc. Indian Acad. Sci. (Math. Sci.) (in press).

[8] Á. BARICZ, R. SzÁsz, Close-to-convexity of some special functions and their derivatives, Bull. Malay. Sci. Soc. 39 (1) (2016), 427-437.

[9] Á. BARICZ, N. YAĞMUR, Radii of starlikeness and convexity of a cross-product of Bessel functions, Ramanujan J. (in press).

[10] R. K. BRown, Univalence of Bessel functions, Proc. Amer. Math. Soc. 11 (2) (1960), 278-283.

[11] E. Kreyszig, J. TodD, The radius of univalence of Bessel functions, Illinois J. Math. 4 (1960), $143-149$.

[12] B. YA. Levin, Lectures on Entire Functions, Amer. Math. Soc.: Transl. of Math. Monographs, vol. $150,1996$.

[13] L. LORCH, Monotonicity of the zeros of a cross-product of Bessel functions, Methods Appl. Anal. 1 (1) (1994), 75-80.

[14] S. M. Shah, S. Y. Trimble, Entire functions with univalent derivatives, J. Math. Anal. Appl. 33 (1971), 220-229.

[15] R. SzÁsz, On starlikeness of Bessel functions of the first kind, In: Proceedings of the 8th Joint Conference on Mathematics and Computer Science, Komárno, Slovakia, 2010, 9 pp. 
[16] R. SzÁsz, P. A. Kupán, About the univalence of the Bessel functions, Stud. Univ. Babeş-Bolyai Math. 54 (1) (2009), 127-132.

[17] G. N. Watson, A Treatise of the Theory of Bessel Functions, Cambridge University Press, Cambridge, 1995. 